\title{
FORMULATING GUIDELINES FOR THE SYSTEMATIC SET- UP OF EXPERIENTIAL MATERIAL CHARACTERIZATION STUDIES: A CASE OF PLASTIC DEMONSTRATORS
}

\author{
Veelaert, Lore (1); \\ Moons, Ingrid (1,2); \\ Du Bois, Els (1) \\ 1: University of Antwerp, Faculty of Design Sciences, Department of Product Development; \\ 2: University of Antwerp, Faculty of Business Economics, Department of Marketing
}

\begin{abstract}
Materials can be considered from a technical and experiential perspective. However, the latter perspective is more complex to study systematically. Four intertwined experiential levels describe the overall materials experience: sensorial, interpretive, affective, and performative level. Building upon the need in experiential material characterization for comparable physical material representations to enable within-material-class comparisons and the inclusion of extensive user aspects, this paper sums up the reasoning process regarding the understanding and design of an experimental set-up and its parameters of a specific case. The case objective is to formulate guidelines for the designer/researcher to set up experiential material characterization experiments with (i) plastic demonstrator forms and (ii) by consumers. Following elements are discussed: Assessors, Stimuli, Interaction Modalities, Dependent variables, Method, and Practical considerations. Next, future experiments can be carried out in order to generate holistic plastic material data on a larger scale, that can be collected in an experiential database and used by designers throughout the design process.
\end{abstract}

Keywords: Multisensory product experience, Experiential material characterization, Materials experience, Emotional design, Human behaviour in design

\section{Contact:}

Veelaert, Lore

University of Antwerp

Product Development

Belgium

lore.veelaert@uantwerpen.be 


\section{INTRODUCTION}

In product design, materials can be considered both from a technical and an experiential perspective. This dualist understanding of materials has gained increased interest over the years (Karana, Pedgley, and Rognoli 2014; Ashby and Johnson 2010; Camere and Karana 2018) and led to a new field of materials experience both in design research and practice (Veelaert, Du Bois, Moons and Karana, 2020). Thus, a holistic approach within the design process does not only require material characterization knowledge with regard to technical properties, manufacturability and functionality that can be historically found in datasheets based on standardized tests (Ashby and Johnson, 2010; Jahan et al., 2010). In addition, the experiences that materials can elicit through physical products should be considered as well to increase commercial success of both products and materials in a competitive market (Karana, Pedgley, and Rognoli 2015; Giaccardi and Karana 2015).

When aiming for a circular economy (Ellen MacArthur Foundation and McKinsey \& Company, 2012) within engineering design, different focuses can be found related to materials, going from materials production, selection and the impact on future waste, to elongating the product use phase through product attachment by means of products and materials that suit the user's personality (Mugge et al., 2005; Norman, 2004). This leads to an increased search for new and alternative materials that are more sustainable and suiting in a circular economy, e.g. natural material, bioplastics, recycled plastics and so on. However, these material's origin impacts both their properties and perceived aesthetics (Karana 2012; Schifferstein and Wastiels 2014; Dehn 2014). Often, such new materials struggle for adoption when introduced in the market, partly due to the lack of knowledge or data on how they are perceived and experienced by people as they are frequently implemented as surrogates or substitute materials (Salvia et al., 2011; Sauerwein et al., 2017; Vezzoli, 2014).

Following the Meanings of Materials Model (Karana 2010), it is the interaction between the user and a material that defines a material's meaning or meanings. However, various factors continuously influence this meaning creation, such as the product in which the material is embodied, its shape and brand, the time and context in which it is used, the background of the user (i.e. gender, age, culture, etc.), and of course the technical properties and experiential qualities of the material itself.

Considering the latter, four experiential levels are defined in literature that are intertwined and as such describe the overall materials experience (Karana, Pedgley, and Rognoli 2015; Camere and Karana 2018; Giaccardi and Karana 2015). The three first levels address the cognitive aspects of experiences, while the final level encompasses the behavioural aspects. First, the sensorial level encompasses the first encounter of our senses with a material and is as such inherently part to human experience (e.g. is the material perceived glossy or light). Within this level, the visual perception of materials and its attributes is highly important in recognizing materials, even without touching (Fleming, 2014, 2017). Second, the interpretive level follows the sensorial encounter and involves the interpretations and meanings people attribute to materials (e.g. is the material associated with masculinity or nostalgia). Third, the affective level includes the emotions that material can unconsciously elicit (e.g. does the material make me feel surprised or fascinated). Fourth, the performative level reflects our physical response or actions to the previous levels (e.g. does the material invite to caress or to fold). Camere and Karana (2018) state that:

"The experiential characterization of materials ... concerns investigating how a material is received, what it makes people think, feel and do. ... Accordingly, the experiential characterization of materials should provide designers with an understanding of what people experience when they encounter a material (e.g. they find it 'surprising', or 'cosy'), to what extent they agree with each other (e.g. how many of them are 'fascinated' by the material), and why they experience a material in the way they do (e.g. what sensorial qualities of the material elicit 'surprise')".

However, Camere and Karana (2018) acknowledge that "materials experiences can be quite challenging to study and research, and it requires a delicate balance between studies that provide both a holistic perspective ... and detailed, specific information". Indeed, a large gap is found in equivalent data support on experiential material knowledge (Piselli et al., 2018; Veelaert, Du Bois, Moons and Karana, 2020; Wilkes et al., 2016). Therefore, they developed the Ma2E4 toolkit for design professionals to facilitate experiential characterization of materials in an agile and inspiring matter. However, the toolkit is rather focused on specific material cases than on large scale material data that is needed for designers. Although the toolkit pays profound attention to the evaluation of various experiential material qualities, it does not involve the physical means or material samples to do so, nor a more structured analysis that can be useful for data driven design. 
Conclusively, this paper aims to formulate guidelines for the systematic set-up of experiential material characterization experiments. By streamlining these studies, material characterizations on a large and standard scale can lead to an experiential database of various materials, helping designers in their design and materials selection process as they are backed by data on materials and target audience (consumers).

When looking at domains such as food science, well-founded tests and statistical procedures for sensory profiling have been embraced (Reinbach et al., 2014; Sidel and Stone, 1993; Varela and Ares, 2012). These have been recently utilized for visual and tactile material characteristics as well (Faucheu et al., 2015; Piselli et al., 2018). Within (interior) architecture, the link between warmth/roughness perception and technical properties of building materials has also been investigated (Wastiels et al., 2012a, 2012b). Conclusively, an extensive literature review (Veelaert, Du Bois, Moons and Karana, 2020) describes how various researchers respond to the methodological challenges involved in experiential material characterization studies, and articulates the need to find "abstract forms or products that do not carry too much meanings in itself so that material meaning can be projected more independently" (Veelaert, Du Bois, Moons and Karana, 2020, p. 13). To achieve a more holistic understanding of materials' experiential qualities, a transition to straightforward and streamlined setups of experiential material characterization studies on a larger scale - facilitating data driven design is still a stumbling block for many material/design researchers.

\section{CASE}

Multiple studies emphasize the specific context or objectives within materials experience studies that require different approaches for this experimental set-up of experiential material characterization (Camere and Karana 2018; Karana and Hekkert 2010). Next to context-specific material data, generic data of experiential material qualities can also offer insights for designers in the beginning of their design process (Veelaert, Du Bois, Moons and Karana, 2020). Hence, experiential studies can start from contextualized materials in a specific product (e.g. (Karana, Hekkert, and Kandachar 2009; Crippa, Rognoli, and Levi 2012)), or can employ abstract, decontextualized samples (e.g. (D'Olivo et al., 2013; Wastiels et al., 2012a)). This way, experimental conditions are easier to control as the material is assessed independent of context. Therefore, this paper builds upon a specific case that arises from previous experiences and needs defined in (Veelaert, Du Bois, Moons and Karana, 2020): (i) need for within-material-class comparisons, (ii) need for physical material representations, and (iii) need for integration of extensive user aspects. First, as little comparisons within material classes can be found - and especially within plastic materials - this case will focus on the facilitation of comparing plastic materials (i.e. virgins, recycled plastics, bioplastics, etc.) that face issues within a circular economy such as sustainable perception or being identity-less imitation materials (Karana and Nijkamp, 2014; Rognoli et al., 2011; Veelaert, Du Bois, Moons, De Pelsmacker, et al., 2020). Furthermore, Fisher (2004) addresses the specific significance of plastic materials for consumers' perception of objects, and its affective consequences. Second, this case employs a standard demonstrator form that is developed in previous research (Veelaert et al., n.d.), see Figure 1, as an answer to the proposed "abstract in-between form that allows an equal and thus constant presentation of various materials, but is varied in itself" (Veelaert, Du Bois, Moons and Karana, 2020). Such a complex demonstrator form allows for more controlled experimental conditions while still facilitation multimodal free exploration of its material.

Third, as a large number of studies involve designers in characterization experiments or limited user aspects beyond age and gender, this case will take on the challenge to specifically address and trigger consumers in a dynamic experiential material characterization as end-users of products/materials. This way, future large-scaled studies can be combined with consumer segmentation for marketing purposes.

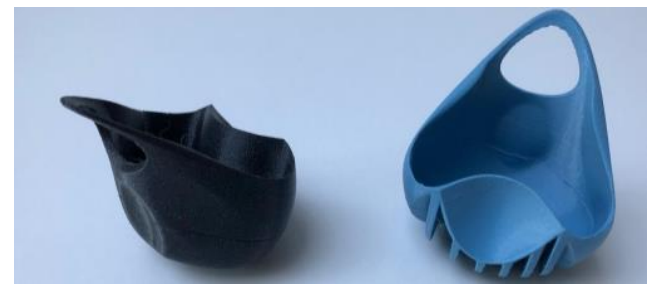

Figure 1. Demonstrator forms shown from two perspectives, based on (Veelaert et al., n.d.). 


\section{RESEARCH AIM}

This paper summarizes the reasoning process and argumentation regarding the experimental set-up and its parameters of a concrete case within materials experience studies. The objective is to formulate guidelines for the designer to systematically set up experiential material characterization experiments with (i) plastic demonstrator forms and (ii) by consumers. Therefore, this research aims to identify a set of appropriate methodological choices as a first step towards streamlined future material characterizations to build up an experiential 'database' of various plastic materials such as virgins, recycled plastics, bioplastics, etc. To structure the work, the next Section is based on the encryption categories of a previous literature review on this matter (Veelaert, Du Bois, Moons and Karana, 2020) and a practical handbook on sensory evaluation (Kemp et al., 2018): (i) stimuli, (ii) interaction modalities, and (iii) dependent variables, (iv) assessors, and (v) method.

\section{GUIDELINES FOR EXPERIMENTAL SET-UP: EXPERIENTIAL MATERIAL CHARACTERIZATION OF PLASTIC DEMONSTRATORS BY CONSUMERS}

\subsection{Assessors}

As previously stated, this case focuses on consumers as participants, as compared to designers or expert sensory panels. Since consumers can be considered as naïve and untrained assessors, and can also be involved in affective judgements. In addition, large-scaled experiential studies with consumers can also offer segmentation opportunities when including extensive user aspects beyond merely age and gender, such as culture, personality traits and values. In the case of continuous experiments over time, a large panel size of consumers can be achieved to generalize findings. The higher the number of assessors, the higher the power of the statistical test that can be performed to analyse the data and improve discrimination between the material stimuli (Kemp et al., 2018). Even for preliminary results, at least thirty assessors per cell are recommended (e.g. at least thirty man and thirty women when comparing material perception based on gender), or preferably even hundred participants (Brysbaert, 2019; Sitanshu Sekhar Kar and A. Ramalingam, 2013; Wilson Vanvoorhis and Morgan, 2007).

\subsection{Stimuli}

Within experiential characterization, the greater part of studies involve physical samples (Veelaert, Du Bois, Moons and Karana, 2020) that are stated by Martín et al. (2015) to be still the standard. However, physical stimuli can reveal themselves in both contextualized product samples and decontextualized abstract samples. For greater experimental control, abstract shaped specimens are often recommended (Piselli et al., 2018; Veelaert et al., 2019, n.d.). As clarified in the previous sections, the physical stimuli in this case involve a set of standard demonstrator forms that are developed specifically for one material class: plastics. However, within-material-class comparisons in this case can still be going from well-known virgin plastics (e.g. PP, PE, ABS), to recycled plastics (both pure and mixed virgins) and bioplastics (e.g. PLA). This material class is chosen as it is not yet studied on its own within experiential characterization although it represents a material class that is familiar and widely used in everyday products. The demonstrator forms shown in Figure 1 is designed to be injection moulded so that high-end quality can be achieved (Veelaert et al., n.d.).

\subsection{Interaction modalities}

As this case is characterized by physical material samples for within-class comparisons (see Section 4.1), the experiment's interaction context is of great importance. Although various interaction modalities and senses can be employed or combined, touch and vision are found to be most dominant within the appraisal of materials (Karana 2009; Sauerwein, Karana, and Rognoli 2017; Schifferstein and Wastiels 2014). This is in contrast to the fact that it is hard to isolate the senses as human behaviour and perception are intrinsically multisensory (Schifferstein 2010; Dacleu Ndengue, Juganaru-Mathieu, and Faucheu 2017). Based on literature (Chen and Chuang, 2014; Veelaert, Du Bois, Moons and Karana, 2020) and the developed demonstrator form (Veelaert et al., n.d.), this case focuses on multimodality through dynamic touch (Hope et al., 2012) and free exploration, and thus approaches the actual phase of use of a product and its material (Crilly et al., 2009; D'Olivo et al., 2013). Conclusively, the complex demonstrator form is aimed at evoking a holistic, multisensory 
interaction, triggering participants into extensive exploration and manipulation of its materials using all senses (Veelaert et al., n.d.). This way, it is possible to facilitate the understanding of all experiential levels, including performative actions such as rubbing, playing, picking up or grabbing a sample (Camere and Karana, 2018; Chen and Chuang, 2014).

\subsection{Dependent variables}

Following the Materials Experience Framework (Karana, Pedgley, and Rognoli 2014) and its practical translation into the Ma2E4 toolkit (Camere and Karana, 2018), four experiential levels can be incorporated as dependent variables within experiential characterization of materials: sensorial, interpretive, affective, and performative. However, the two first levels are most commonly involved in past experiments (Veelaert, Du Bois, Moons and Karana, 2020) and in the development of the demonstrator form (Veelaert et al., n.d.), as they are usually more approached from a semi-quantitative perspective in contrast to a more qualitative evaluation of emotions or the observation of performative actions.

The vocabulary of the Ma2E4 toolkit mentions twelve sensorial attributes (hard/soft, smooth/rough, matte/glossy, not reflective/reflective, cold/warm, not elastic/elastic, opaque/transparent, tough/ductile, strong/weak, light/heavy, regular texture/irregular texture, fibred/not-fibred), eleven meaning sets (aggressive/calm, cosy/aloof, elegant/vulgar, frivolous/sober, futuristic/nostalgic, masculine/feminine, ordinary/strange, sexy/not sexy, toy-like/professional, natural/unnatural, hand-crafted/manufactured), twenty emotions (frustration, boredom, disappointment, reluctance, confusion, rejection, disgust, melancholy, distrust, doubt, love, amusement, surprise, confidence, enchantment, respect, attraction, curiosity, fascination, comfort), and proposes twenty-two actions (pressing, rubbing, grazing, compressing, poking, caressing, fiddling, pounding, pushing, folding, lifting, weighting, bending, flexing, picking, squeezing, smelling, holding, seizing, pinching, grabbing, grasping...), see also (Angelini et al., 2015; Cutkosky, 1989; Lederman and Klatzky, 2009). However, additional experiential qualities can be interesting for characterization experiments too, as used in previous work focussing on (recycled) plastics (Veelaert et al., n.d.; Veelaert, Du Bois, Moons, De Pelsmacker, et al., 2020).

A final consideration relates to assessing the experiential levels one by one or randomly mixing them together. For the ease of understanding for consumers, and following the structure of the Ma2E4 toolkit, we propose to sequentially assess attributes per experiential level in the context of this specific case.

\subsection{Method}

\subsubsection{Measurement of constructs}

Although some experiential qualities might be less relevant in the context of plastics, a more important consideration comes into play, next to the extensive list of attributes available. The measurement of these experiential constructs can be done in different ways, but should ideally be streamlined for future database building. Largely derived from marketing research and sensory evaluation within food science, four main categories of sensory tests can be distinguished: descriptive testing, discrimination testing, hedonic test, and free impressions. However, within experiential material characterization, descriptive scaling method by means of the semantic differential scaling method (SDM) (Osgood et al., 1957) is most frequently used (Hsu et al., 2000; Petiot and Yannou, 2004; Veelaert, Du Bois, Moons and Karana, 2020). It has also been applied in the sensorial scales of Karana et al. (Karana, Hekkert, and Kandachar 2010; Karana, Hekkert, and Kandachar 2009) and within the Ma2E4 toolkit for the characterization of sensorial attributes (using clarifying pictograms for untrained respondents) and interpretive characteristics (Camere and Karana, 2018). To provide a midpoint for neutrality, an odd number of scale points is preferred (Lilley et al., 2016) and approaches a more interval-based scale. Moreover, odd scales are used in $85 \%$ of past experiential scaling experiments (Veelaert, Du Bois, Moons and Karana, 2020) that employ usually five (preferred for translation into experiential characterization map; (Camere and Karana, 2018)) or seven points (for more detail).

With regard to this paper's case, we propose to stay consistent and adopt these unstructured scales with pairs of bipolar adjectives at the beginning and end of the scales (Ledahudec et al., 1992). However, in order to converge interval-based statistical potential, equal distances should be emphasized by using signed numbers between the opposite pairs, preferably with a continuous slider as well so that participants can select any point between 1 and 5 or between -2 and +2 . For example, the scale of the sensorial attribute Glossiness looks like "Very glossy -2, -1, 0, 1, 2 Very matte". 


\subsubsection{Experimental design structure}

Randomisation is an important factor to consider in the experimental design of material characterization studies, especially in large-scaled experiments. In order to minimize fatigue and order effects it is recommended to randomize (i) the selection, (ii) the order, and (iii) the position (left versus right) of the experiential qualities/pairs. Of course, this implies that it is more easily done through a digital survey as compared to characterization exercises on paper. Section 4.3 already summed up the extensive list of experiential qualities over four levels, but only a selection can be questioned at once per participant, leading to a between-subjects design that is easier to set up, shorter and slightly minimizes learning and transfer across conditions (Charness et al., 2012). Moreover, when the aim is to experientially characterize 'all plastics', i.e. a great variety of plastic variations over time, a random selection of available material stimuli must be made as well, leading to another between-subjects factor. This combination is defined as a balanced incomplete block (BIB) design and requires specific data analysis such as analysis of variance or ANOVA (Kemp et al., 2018).

With regard to sample presentation techniques, a serial or sequential monadic design is most common, in which material samples are presented independently, one after another (Kemp et al., 2018). However, for within-material-class comparisons of plastic demonstrators in this case, a reference framework by means of a simultaneous comparative design could be more beneficial for untrained consumers that might find it easier to asses stimuli in relation to each other instead of absolute (Cleaver, 2018), since human perception is inherently holistic and comparative (Pagès et al., 2010). Thus, this way participants are given a random set of material demonstrators that each need to be assessed are allowed to reassess and compare multiple materials with each other.

\subsubsection{Factors affecting measurements}

Consumer judgements can be easily influenced by bias due to psychological factors, as summed up by (Kemp et al., 2018). In the context of experiential material characterization, several errors can be expected of which one should be aware in setting up experiments. First, stimulus errors occur when assessors focus on prior knowledge when rating a sample (clues such as packaging or style), instead of their perception of the material itself. We aim to diminish this effect by providing standard demonstrator forms so that irrelevant influence of contextual factors is downsized or at least kept constant over multiple materials. Second, halo effects or proximity errors occur when (untrained) assessors score consecutive attributes in a similar way as compared to when these attributes would be questioned separately. This effect can be expected with untrained assessors, but can be countered by involving a limited number of attributes, separating sensorial attributes versus interpretive characteristics, and randomising their order. Third and similarly, order effects occur when an assessor is influenced by the order of questions, samples or attributes. This can be decreased by randomizing the order of material sample presentation. Fourth, central tendency errors occur when participants avoid extremes and prefer scale middle points, but can be reduced by exposing them to a wide range of samples and a large enough scale. Overall, the combination of using the proposed standard demonstrator forms as material stimuli (Section 4.2), as well as a randomisation of both stimuli and attributes (Section 4.5.2), is expected to reduce these errors in experiments of experiential material characterization.

\subsubsection{Practical}

Finally, practical considerations also count in setting up experiential material characterization experiments. Both budget and feasibility depend on the timing or test duration that is possible and desirable. Previous literature review (Veelaert, Du Bois, Moons and Karana, 2020) reveals that the number of stimuli in experiential material characterization experiments varies between 3-96 material samples with a median of 10 samples. The number of scale items differs between 1-34 items with a median of 10 items. When taking into account both the number of stimuli and the number of semantic scales that need to be assessed for each material sample, a delicate balance must be intended. Therefore, we propose to aim for 3-5 material samples that are assessed on 5-10 experiential attribute pairs, balancing a total of 25-30 assessments to be made by each participant. Overall, a maximum total time of twenty minutes per experiment seems achievable, including segmentation questions. When the motivation of the consumer can be increased by appropriate feedback or fun elements, different scenarios could be proposed, i.e. a short, medium and long version of the test, so that one can choose to repeat the experiment with additional materials and/or attributes. 


\section{Discussion}

Although this paper presents guidelines for an experimental design that is limited to our own case of experiential material characterization, several aspects can be generalized within this scenario. First of all, it is important to define the aim of the experiential study: is the objective to generate qualitative experiential information about one new material that can be applied in a specific project (e.g. Material Driven Design), or is it to compare a broad set of different materials with one another? The former option is more case-specific and allows to go more in detail and collect more qualitative material information, while the later sprouts from a more holistic perspective to collect data on a large scale which offers opportunities to link this data to consumer segmentation information. Overall, we see opportunities in always comparing materials in the beginning of setting up an experiential database, while in the end when a basic amount of data has been generated, new data can be added by means of specific material studies.

In addition, when focussing on a holistic or generic perspective when collecting experiential material data, it is important to consider the importance of context within materials experience. Indeed, meanings of materials are influenced by contextual factors such as the products they are embodied in, where these products are used. To overcome this context issue, the proposed guidelines build upon the use of an abstract demonstrator form that is aimed to be independent of context, to allow controlled experimental conditions. However, when conducting characterization experiments with these demonstrator forms, it is possible to include "envisioning factors" by asking participants to envision the demonstrator's material in a particular product or situation. Thus, the abstract form can offer flexibility despite standardization of the form, and as such increase time efficiency and practical difficulties.

Conclusively, the next step in future research should be to start carrying out experiential characterization studies following the proposed guidelines and thus, gather experiential data on a large set of plastic materials such as virgins, bioplastics and recycled plastics (data-driven design). Together with largescale information on user aspects (of consumers), relationships can be sought between different types of plastics and their (sustainable) perception in order to facilitate their commercial success in a circular economy.

\section{CONCLUSION}

In this paper, we presented a selection of experimental guidelines that can be further used by designers to set up experiential material characterization studies within a specific case in which we focus on plastic materials (virgins, recycled, bioplastics, etc.), made physical by means of standard demonstrator forms, and assessed by consumers. A schematic overview of these guidelines is presented in Figure 2.

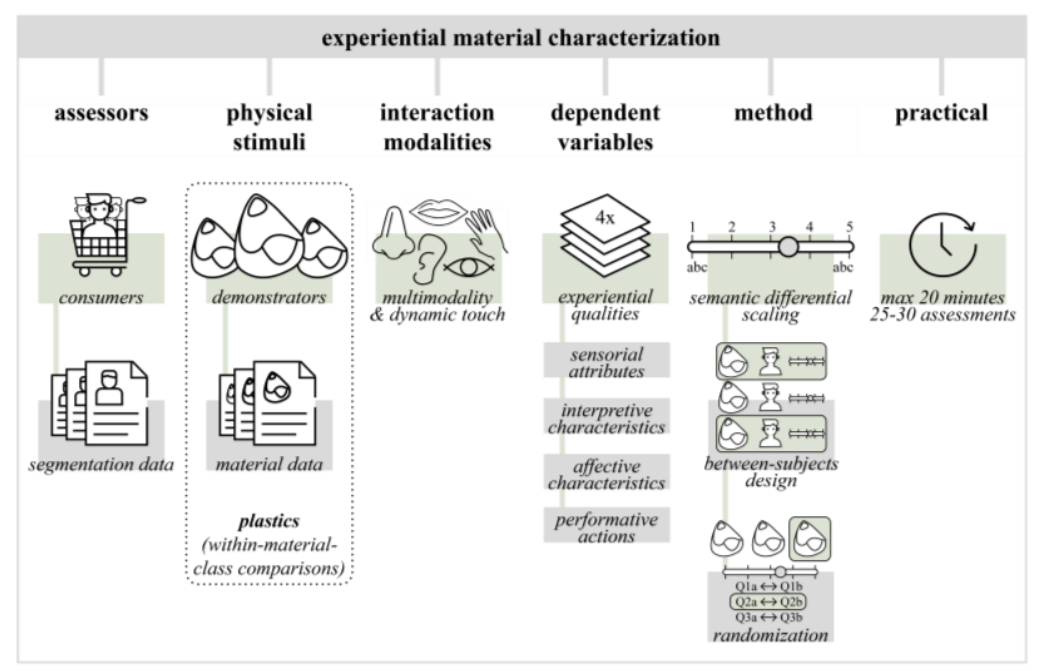

Figure 2. Schematic overview of guidelines for experiential characterization studies.

To sum up, an experimental design involving the following elements was proposed: (i) experiential characterization by consumers in large-scales studies for segmentation opportunities based on more extensive user aspects, (ii) standard physical demonstrator form in various plastics for greater experimental control and within-material-class comparisons, (iii) approaching use phase through 
multimodality and dynamic touch to offer an holistic, multisensory interaction with extensive material exploration to facilitate the characterization of all experiential levels, (iv) assessing qualities within these experiential levels separately instead of mixed together to ease understanding, (v) and by using the semantic differential scaling method with five-point scales, a continuous slider and signed numbers between opposite pairs, (vi) a between-subjects design with randomization of the selection, order and position of experiential qualities on scales, as well as a random selection of a set of plastic demonstrators in a comparative design set-up, (vii) and finally aiming for a balance of 25 to 30 assessments (material $\mathrm{x}$ quality) per participant within a total duration of twenty minutes.

To conclude, we hope these guidelines offer a common starting point for design researchers to set up experiential characterization studies with consumers and plastic materials so that experiential data can be gathered and shared on a large scale, and relationships with extensive user aspects can be investigated.

\section{ACKNOWLEDGMENTS}

For this work, funding was granted by the University of Antwerp (BOF-DOCPRO 2017, grant number 34719).

\section{REFERENCES}

Angelini, L., Lalanne, D., van den Hoven, E., Khaled, O.A. and Mugellini, E. (2015), "Move, hold and touch: A framework for Tangible gesture interactive systems", Machines, MDPI AG, Vol. 3 No. 3, pp. 173-207. https://dx.doi.org/10.3390/machines3030173.

Ashby, M.F. and Johnson, K. (2010), Materials and Design: The Art and Science of Material Selection in Product Design, Elsevier/Butterworth-Heinemann. https://dx.doi.org/10.1016/C2009-0-26530-5

Brysbaert, M. (2019), "How Many Participants Do We Have to Include in Properly Powered Experiments? A Tutorial of Power Analysis with Reference Tables", Journal of Cognition, Ubiquity Press, Ltd., Vol. 2 No. 1, pp. 1-38. https://dx.doi.org/10.5334/joc.72.

Camere, S. and Karana, E. (2018), "Experiential characterization of materials: Toward a toolkit”, International Conference on Design Research Society (DRS), Limmerick, Ireland, 25-28th June. https://dx.doi.org/10.21606/dma.2017.508.

Charness, G., Gneezy, U. and Kuhn, M.A. (2012), "Experimental methods: Between-subject and within-subject design", Journal of Economic Behavior and Organization, North-Holland, Vol. 81 No. 1, pp. 1-8. https://dx.doi.org/10.1016/j.jebo.2011.08.009.

Chen, Y.T. and Chuang, M.C. (2014), "The study of tactile feeling and It's expressing vocabulary", International Journal of Industrial Ergonomics, Vol. 44 No. 5, pp. 675-684. https://dx.doi.org/10.1016/j.ergon.2014.07.003.

Cleaver, G. (2018), "Ranking and Rank-Rating”, Descriptive Analysis in Sensory Evaluation, John Wiley \& Sons, Ltd, Chichester, UK, pp. 447-491. https://dx.doi.org/10.1002/9781118991657.ch12.

Crilly, N., Moultrie, J. and Clarkson, P.J. (2009), "Shaping things: intended consumer response and the other determinants of product form”, Design Studies, Elsevier, Vol. 30 No. 3, pp. 224-254.

Crippa, G., Rognoli, V. and Levi, M. (2012), "Materials and emotions: A study on the relations between materials and emotions in industrial products", 8th International Design and Emotion Conference, London. https://dx.doi.org/10.1016/j.destud.2008.08.001.

Cutkosky, M.R. (1989), "On Grasp Choice, Grasp Models, and the Design of Hands for Manufacturing Tasks”, IEEE Transactions on Robotics and Automation, Vol. 5 No. 3, pp. 269-279. https://dx.doi.org/10.1109/70.34763.

D’Olivo, P., Curto, B.J. Del, Faucheu, J., Lafon, D., BASSEREAU, J.-F. and Sébastien, L. (2013), “Sensory Metrology: When Emotions and Experiences Contribute to Design", Proceedings of the International Conference on Engineering Design, ICED13 (Vol. 7 DS75-07), Seoul, Korea, 19-22th August, pp. 507-516.

Dacleu Ndengue, J., Juganaru-Mathieu, M. and Faucheu, J. (2017), "Material perception and material identification in product design", Proceedings of the International Conference on Engineering Design, ICED, Vol. 8, Vancouver, pp. 429-437.

Dehn, J. (2014), "Conception and realization of a sustainable materials library”, in Karana, E., Pedgley, O. and Rognoli, V. (Eds.), Materials Experience: Fundamentals of Materials and Design, Butterworth-Heinemann, Oxford, UK, pp. 155-168.

Ellen MacArthur Foundation and McKinsey \& Company. (2012), Towards the Circular Economy, edited by McKinsey \& Company, Ellen MacArthur Foundation, Isle of Wight, United Kingdom.

Faucheu, J., Caroli, A., Del Curto, B. and Delafosse, D. (2015), "Experimental Setup for Visual and Tactile Evaluation of Materials and Products Through Napping® Procedure”, in Christian Weber, Stephan Husung, Gaetano Cascini, Marco CantaMESsa, Dorian Marjanovic, M.B. (Ed.), Proceedings of the 20th International Conference on Engineering Design (ICED 15), Milan, Italy, pp. 129-138. 
Fisher, T.H. (2004), "What We Touch, Touches Us: Materials, Affects, and Affordances”, Design Issues, MIT Press - Journals, Vol. 20 No. 4, pp. 20-31. https://dx.doi.org/10.1162/0747936042312066.

Fleming, R.W. (2014), "Visual perception of materials and their properties", Vision Research, Pergamon, Vol. 94, pp. 62-75. https://dx.doi.org/10.1016/J.VISRES.2013.11.004.

Fleming, R.W. (2017), "Material Perception”, Annual Review of Vision Science, Annual Reviews Inc., Vol. 3 No. 1, pp. 365-388. https://dx.doi.org/10.1146/annurev-vision-102016-061429.

Giaccardi, E. and Karana, E. (2015), "Foundations of Materials Experience”, Proceedings of the 33rd Annual ACM Conference on Human Factors in Computing Systems - CHI '15, ACM Press, New York, New York, USA, pp. 2447-2456. https://dx.doi.org/10.1145/2702123.2702337.

Hope, A.D., Jones, M. and Zuo, H. (2012), "Sensory perception in materials selection for industrial/product design”, International Journal of Designed Objects, Vol. 6 No. 3, pp. 17-31. https://dx.doi.org/10.18848/2325-1379/cgp/v06i03/38662.

Hsu, S.H., Chuang, M.C. and Chang, C.C. (2000), "A semantic differential study of designers' and users' product form perception", International Journal of Industrial Ergonomics, Elsevier Science Publishers B.V., Vol. 25 No. 4, pp. 375-391. https://dx.doi.org/10.1016/S0169-8141(99)00026-8.

Jahan, A., Ismail, M.Y., Sapuan, S.M. and Mustapha, F. (2010), "Material screening and choosing methods - A review", Materials and Design, Vol. 31 No. 2, pp. 696-705. https://dx.doi.org/10.1016/j.matdes.2009.08.013.

Karana, E. (2009), Meanings of Materials (Doctoral Dissertation), Delft University of Technology, Delft, the Netherlands.

Karana, E. (2010), "How do Materials Obtain Their Meanings?”, METU Journal of Faculty of Architecture, Vol. 27 No. 2, pp. 271-285. https://dx.doi.org/10.4305/METU.JFA.2010.2.15.

Karana, E. (2012), "Characterization of 'natural' and 'high-quality' materials to improve perception of bioplastics”, Journal of Cleaner Production, Elsevier, Vol. 37, pp. 316-325. https://dx.doi.org/10.1016/j.jclepro.2012.07.034.

Karana, E. and Hekkert, P. (2010), "User-Material-Product Interrelationships in Attributing Meanings", International Journal of Design, Vol. 3 No. 43-52, available at: http://www.ijdesign.org/index.php/IJDesign/article/view/635/312 (accessed 20 February 2019).

Karana, E., Hekkert, P. and Kandachar, P. (2009), “Assessing material properties on sensorial scales”, 2009 ASME International Design Engineering Technical Conferences and Computers and Information in Engineering Conference, DETC2009, Vol. 2, American Society of Mechanical Engineers,U.S. (2009), San Diego, California, USA, 30th August-2th September, pp. 911-916. https://dx.doi.org/10.1115/DETC2009-86756.

Karana, E., Hekkert, P. and Kandachar, P. (2010), “A tool for meaning driven materials selection”, Materials and Design, Vol. 31 No. 6, pp. 2932-2941. https://dx.doi.org/10.1016/j.matdes.2009.12.021.

Karana, E. and Nijkamp, N. (2014), "Fiberness, reflectiveness and roughness in the characterization of natural and high quality materials", Journal of Cleaner Production, Elsevier, Vol. 68, pp. 252-260. https://dx.doi.org/10.1016/J.JCLEPRO.2014.01.001.

Karana, E., Pedgley, O. and Rognoli, V. (2014), Materials Experience: Fundamentals of Materials and Design, 1st ed., Butterworth-Heinemann, Oxford, UK, available at: https://doi.org/https://doi.org/10.1016/C2012-002198-9.

Karana, E., Pedgley, O. and Rognoli, V. (2015), “On materials experience”, Design Issues. https://dx.doi.org/10.1162/desi_a_00335

Kemp, S.E., Hort, J. and Hollowood, T. (2018), Descriptive Analysis in Sensory Evaluation, edited by Kemp, S.E., Hort, J. and Hollowood, T., John Wiley \& Sons, Ltd, Chichester, UK. https://dx.doi.org/10.1002/9781118991657.

Ledahudec, J., Pilková, L. and Pokorný, J. (1992), “Comparison of structured and unstructured graphical scales for the evaluation of sensory quality", Food / Nahrung, Vol. 36 No. 1, pp. 96-98. doi:http://doi.wiley.com/10.1002/food.19920360116.

Lederman, S.J. and Klatzky, R.L. (2009), "Haptic perception: A tutorial", Attention, Perception, and Psychophysics, Springer. https://dx.doi.org/10.3758/APP.71.7.1439.

Lilley, D., Smalley, G., Bridgens, B., Wilson, G.T. and Balasundaram, K. (2016), "Cosmetic obsolescence? User perceptions of new and artificially aged materials", Materials \& Design, Elsevier, Vol. 101, pp. 355-365. https://dx.doi.org/10.1016/J.MATDES.2016.04.012.

Martín, R., Iseringhausen, J., Weinmann, M. and Hullin, M.B. (2015), "Multimodal perception of material properties", Proceedings of the ACM SIGGRAPH Symposium on Applied Perception - SAP '15, ACM Press, New York, New York, USA, pp. 33-40. https://dx.doi.org/10.1145/2804408.2804420.

Mugge, R., Schifferstein, H.N.J. and Schoormans, J.P.L. (2005), "Product Attachment and Product Lifetime: the Role of Personality Congruity and Fashion", ACR European Advances, Vol. E-07, available at: http://www.acrwebsite.org/volumes/13725/eacr/vol7/E-07 (accessed 11 April 2019).

Norman, D.A. (2004), Emotional Design - Why We Love (or Hate) Everyday Things, Basic Books, New York. https://doi.org/10.1111/j.1537-4726.2004.133_10.x

Osgood, C.E., Suci, G.J. and Tannenbaum, P.H. (1957), The Measurement of Meaning, USA: University of Illinois Press. 
Pagès, J., Cadoret, M. and Lê, S. (2010), “The Sorted Napping: A New Holistic Approach in Sensory Evaluation”, Journal of Sensory Studies, Wiley/Blackwell (10.1111), Vol. 25 No. 5, pp. 637-658. https://dx.doi.org/10.1111/j.1745-459X.2010.00292.x.

Petiot, J.-F. and Yannou, B. (2004), "Measuring consumer perceptions for a better comprehension, specification and assessment of product semantics", International Journal of Industrial Ergonomics, Elsevier, Vol. 33 No. 6, pp. 507-525. https://dx.doi.org/10.1016/J.ERGON.2003.12.004.

Piselli, A., Baxter, W., Simonato, M., Del Curto, B. and Aurisicchio, M. (2018), "Development and evaluation of a methodology to integrate technical and sensorial properties in materials selection", Materials \& Design, Elsevier, Vol. 153, pp. 259-272. https://dx.doi.org/10.1016/J.MATDES.2018.04.081.

Reinbach, H.C., Giacalone, D., Ribeiro, L.M., Bredie, W.L.P. and Frøst, M.B. (2014), "Comparison of three sensory profiling methods based on consumer perception: CATA, CATA with intensity and Napping®", Food Quality and Preference, Vol. 32, pp. 160-166. https://dx.doi.org/10.1016/j.foodqual.2013.02.004.

Rognoli, V., Salvia, G. and Levi, M. (2011), "The aesthetic of interaction with materials for design: the bioplastic's identity", Proceedings of the 2011 Conference on Designing Pleasurable Products and Interfaces - DPPI '11, ACM Press, New York, USA, p. 1. https://dx.doi.org/10.1145/2347504.2347540.

Salvia, G., Ostuzzi, F., Rognoli, V. and Levi, M. (2011), "The value of imperfection in sustainable design: the emotional tie with perfectible artefacts for longer lifespan”, Sustainability in Design: Now! Challenges and Opportunities Of Design Research, Education and Practice in the XXI Century, Abstracts, Bangalore, India, 29th September-1th October.

Sauerwein, M., Karana, E. and Rognoli, V. (2017), "Revived Beauty: Research into Aesthetic Appreciation of Materials to Valorise Materials from Waste", Sustainability, Multidisciplinary Digital Publishing Institute, Vol. 9 No. 4, p. 529. https://dx.doi.org/10.3390/su9040529.

Schifferstein, H. and Wastiels, L. (2014), "Sensing materials: Exploring the building blocks for experiential design”, in Karana, E., Pedgley, O., Rognoli, V. (Ed.), Materials Experience: Fundamentals of Materials and Design, 1st ed., Butterworth Heinemann, Oxford, pp. 15-26. https://dx.doi.org/10.1016/B978-0-08099359-1.00002-3.

Schifferstein, H.N.J. (2010), "From salad to bowl: The role of sensory analysis in product experience research", Food Quality and Preference, Elsevier, Vol. 21 No. 8, pp. 1059-1067. https://dx.doi.org/10.1016/J.FOODQUAL.2010.07.007.

Sidel, J.L. and Stone, H. (1993), "The role of sensory evaluation in the food industry", Food Quality and Preference, Elsevier, Vol. 4 No. 1-2, pp. 65-73. https://dx.doi.org/10.1016/0950-3293(93)90314-V.

Sitanshu Sekhar Kar and A. Ramalingam. (2013), "Is 30 the magic number? issues in sample size estimation", National Journal of Community Medicine, Vol. 4 No. 1, pp. 175-179.

Varela, P. and Ares, G. (2012), "Sensory profiling, the blurred line between sensory and consumer science. A review of novel methods for product characterization", Food Research International, Vol. 48 No. 2, pp. 893-908. https://dx.doi.org/10.1016/j.foodres.2012.06.037.

Veelaert, L., Du Bois, E., Moons, I. and Karana, E. (2020), "Experiential characterization of materials in product design: A literature review”, Materials \& Design, Elsevier, Vol. 190, p. 108543. https://doi.org/10.1016/j.matdes.2020.108543

Veelaert, L., Du Bois, E., Moons, I., De Pelsmacker, P., Hubo, S. and Ragaert, K. (2020), “The Identity of Recycled Plastics: A Vocabulary of Perception”, Sustainability, Multidisciplinary Digital Publishing Institute, Vol. 12 No. 5, p. 1953. https://doi.org/10.3390/su12051953

Veelaert, L., Moons, I., Van Gogh, D., Vleugels, J. and Du Bois, E. (under review). "A Physical Demonstrator Form for Experiential Material Characterization", International Journal of Designed Objects.

Veelaert, L., Moons, I., Rohaert, S. and Du Bois, E. (2019), “A Neutral Form for Experiential Material Characterisation", Proceedings of the Design Society: International Conference on Engineering Design, Cambridge University Press (CUP), Vol. 1 No. 1, pp. 1743-1752. https://doi.org/10.1017/dsi.2019.180.

Vezzoli, C. (2014), "The 'Material' Side of Design for Sustainability”, in Karana, E., Pedgley, O., Rognoli, V., E. (Ed.), Materials Experience: Fundamentals of Materials and Design, Butterworth Heinemann, Oxford, UK, pp. 105-121. https://dx.doi.org/10.1016/B978-0-08-099359-1.00008-4.

Wastiels, L., Schifferstein, H.N.J., Heylighen, A. and Wouters, I. (2012a), "Red or rough, what makes materials warmer?", Materials \& Design, Elsevier, Vol. 42, pp. 441-449. https://dx.doi.org/10.1016/J.MATDES.2012.06.028.

Wastiels, L., Schifferstein, H.N.J., Heylighen, A. and Wouters, I. (2012b), "Relating material experience to technical parameters: A case study on visual and tactile warmth perception of indoor wall materials", Building and Environment, Pergamon, Vol. 49, pp. 359-367. https://dx.doi.org/10.1016/J.BUILDENV.2011.08.009.

Wilkes, S., Wongsriruksa, S., Howes, P., Gamester, R., Witchel, H., Conreen, M., Laughlin, Z., et al. (2016), "Design tools for interdisciplinary translation of material experiences", Materials \& Design, Vol. 90, pp. 1228-1237. https://dx.doi.org/10.1016/j.matdes.2015.04.013.

Wilson Vanvoorhis, C.R. and Morgan, B.L. (2007), Understanding Power and Rules of Thumb for Determining Sample Sizes, Tutorials in Quantitative Methods for Psychology, Vol. 3. https://doi.org/10.20982/tqmp.03.2.p043 